\title{
A Study and Analysis in Database Design by MERISE.
}

Kasereka Masivi Samuel ${ }^{\# 1}$, Ravi Shankar Shukla ${ }^{\# 2}$

\#1 Inverstis University Bareilly India, +243 994010 549, samasivi@yahoo.fr \#2 Saudi Electronic University, Saudi Arabia, +966591296155, ravipraful@,gmail.com

\section{ABSTRACT}

Up-front handling of the prior and specific factors in the design of database is ar important factor that can influence of its exactitude and useless. In this paper, we aim a highlighting the importance of a study and analysis of an existing system to design a databas through MERISE methodology.

Key words: Study and Analysis, Design, Database, MERISE.

Corresponding Author: Kasereka Masivi Samuel, samasivi@yahoo.fr, +243994010549

\section{INTRODUCTION}

Actually, the analysis and design of information systems has most of the time vocation to allow the creation of databases, which must represent as closely as possible the reality of the field studied thus requiring the use of a design method [1].

Note that the databases designed using these methods are either local or distributed. The scenario for designing can be presented like this:

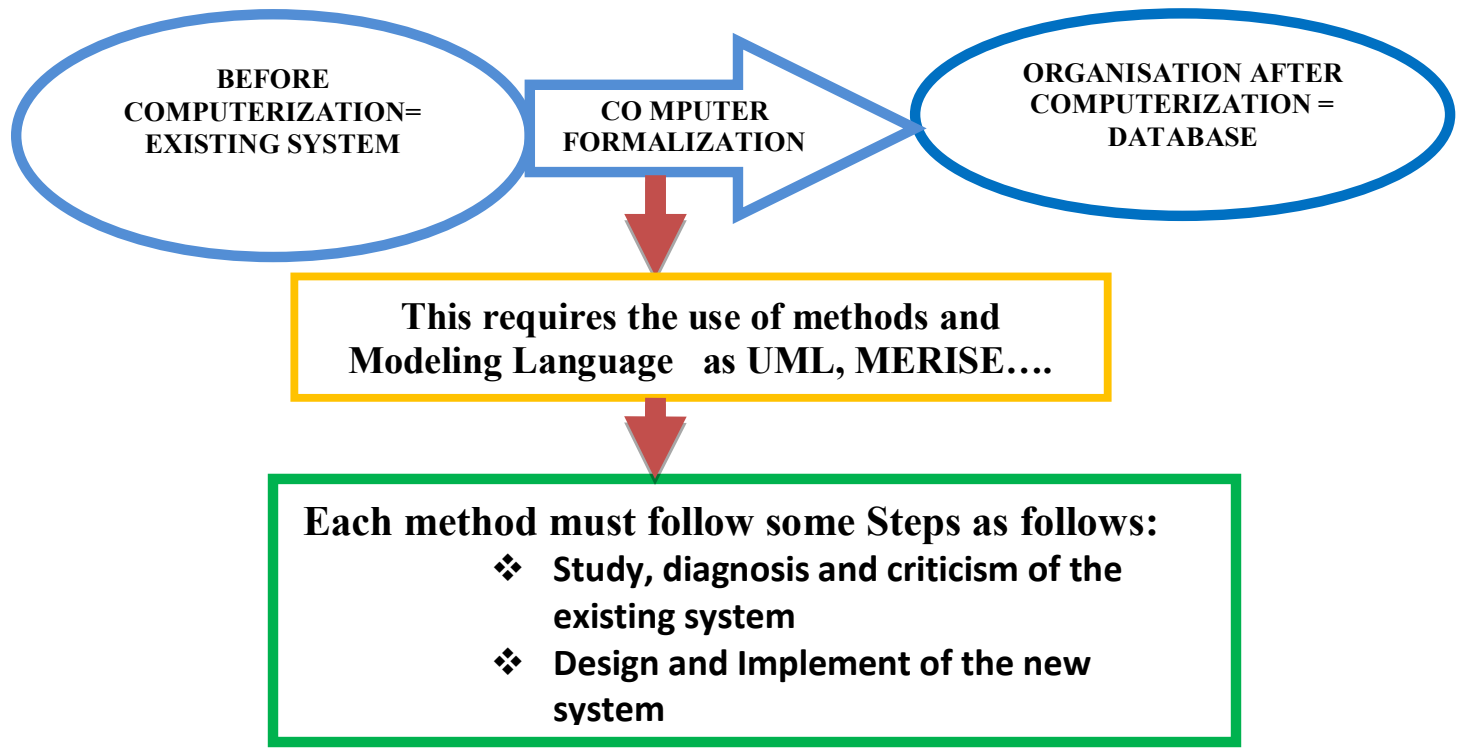

Indeed, as confirmed by Pierre-Alain MULLER and Nathalie GAERTNER, "computer has imperceptibly crept into all of our daily practical activities, thus, the method must be the most appropriate tool in all areas of microeconomic and macroeconomic life, where information needs to be dealt with reliably and efficiently" [2]. Thus, designing of distributed database needs, like any other database, methodology; however, we found that, the design technologies are more oriented towards the design of local databases than to distributed databases and this causes a methodological problem for distributed databases. All conception methods aim at [3]: 
Knowing the needs of the users;

$>$ Analyzing these needs;

$>$ Then conceiving models and interfaces for a development in a programming language and Database Management System.

Likewise, the development of technology, business management is meant to modernize too. As it becomes increasingly dangerous to rely on humans to perform tasks slowly, with inaccuracy, fatigue that causes problem of promptness in submitting reports then technology is called to the rescue. One of the recommended techniques is the use of certain spreadsheets like Ms Excel for sort, filters and calculations. But these techniques encounter difficulties in easy data entry and easy reporting; similarly, these techniques do not resist certain types of viruses.

One way to solve this problem is to design databases. But some databases, not being useful, do not solve the above difficulties because their conceptions have no prior analysis and if this has been done, perhaps did not respect the principles of analysis, design and implementation, nevertheless, if some databases have not had classic analysis and design, can succeed with the strong experience of designers and programmers.

So it is in this light, that this study care out an analysis of the existing system for the Congolese Computer Centre through MERISE methodology and highlighting the importance of an analysis of existing system.

\section{MATERIALS AND METHODS}

To achieve our objectives, we used several methods and techniques including: the method of study and realization of computer projects for the organization systems (MERISE= Methode d'Etudes et des Réalisations en Informatique pour les systèmes d'Entreprise) [4] that allowed us to do modeling; the literature review identified the principles and clarify the concepts, while observation and oral interview helped us to come into direct contact with reality to deal with.

\section{RELATED WORKS}

Several authors have spoken of a distributed database, some in the sense of their creation in any database management system, others in the sense of their design; without highlighting the risk related to the implementation or the usefulness of the database created during non-compliance with certain crucial steps including the study, diagnosis and criticism of the existing system.

Michelle CLOUSE brings a practical guide that describes different steps, step by step and with many examples, from the expression of user needs to the design of a standardized relational database that meets their demand; nevertheless, he did not emphasize the importance of analyzing the existing situation [5]. Gérard Bueno first introduces the fundamental elements of design by proposing more sophisticated modeling solutions to take into account more complex situations through exercises and problems solved [6].

Coulouris, Dollimore, Mary, Kindberg, Silberschatz, Korth and Sudarshan have developed some principles and practice of distributed computer systems and interesting developments, using a number of cases of modern studies to illustrate their design and development. These techniques have allowed readers to evaluate existing distributed systems and design new systems [7].

Gilles Roy, gives a predominant importance to the conceptual model of data analysis in the design by proposing rules, techniques, tips and warnings illustrated by numerous examples and case studies which adopt the notation UML by integrating the techniques of 
modeling and derivation rules within a logical and real-world continuum by providing the necessary support for the success of a database design project and the consistency of models [8]. Dessai has more talked about how to create distributed databases, its advantages and disadvantages, and other types of database [9].

Jean-Luc Baptiste in his book on the MERISE method, gives a simple, direct and practical information on the MERISE method and the SQL language. How to realize the different models (conceptual models, logical models, physical models) but also the models specific to treatments (conceptual models of treatments, organizational models of treatments ...); Model with MERISE / 2 extensions; Compare some MERISE models to some UML diagrams, the SQL language is presented in a progressive way and is illustrated by numerous examples to learn how to manipulate, filter, sort, group data; Create, modify, delete tables; Assign or remove rights to certain users [10]. Through his work, Georges Gardarin brings precise definitions of concepts, an illuminating approach of algorithms and methods, many for the design of databases [11].

Elmasri Ramez and Shamkant Navathe present in their book the fundamental concepts necessary for the design, implementation and use of database systems and applications. They reviewed some of the most important aspects such as design, relational database management systems, transaction processing, disaster recovery techniques, and so on [12]. Christian Soutou, explains how to build a conceptual model in the form of a class diagram, how to transform it into a model of relational or object-relational data, in order to finally generate the desired SQL2 or SQL3 code [13].

Said Benaïchou in his book offers students and teachers very useful in-depth knowledge in the design and management of databases, the use of the SQL language describing the relational model, SQL, query optimization and transactions and data modeling [14].

Arnold Rochfeld and José Moréjon presented concretely in their book some notions concerning the characteristics of MERISE, collection of Existing, the elaboration of data models, the development of treatment models, the conceptual description of the future system, the organizational description of the future system and the operational description of a future system. The latter spoke of the collection of the existing not in the sense of wanting to probe and criticize but only in the sense of the harvest to have the design elements of the new system [15].

Imad Saleh proposes a progressive and rigorous approach, centered on the relational approach of the databases as well on the practical as theoretical level, by relying on the big systems of databases as well as his realized system. It also addresses the fundamental problems of implementing a database supported by numerous practical exercises are proposed for each chapter [16]. Dominique Dionisi expose d'une manière claire et concise les principaux aspects de Merise s'appuyant sur de nombreux exemples et schémas pour éclairer des concepts parfois ardus [17].

Hubert Tardieu et al, in their book, describe the principles and tools of the MERISE Method, which for over twenty years has inspired many other methods, particularly recently in synergy with object-oriented approaches. They also show that in order to design the database or to define the automated management processes that will support the company's internal systems or applications intended for the public, the MERISE Method provides the essential bases that must be implemented in the technological context of the moment [18].

Baptiste and Jean-Luc provide simple, direct and practical information on the Merise method and the SQL language.

In the section on the MERISE method, they show how to realize the different models (conceptual models, logical models, physical models) but also models specific to treatments 
(conceptual models of treatments, organizational models of treatments ...); model with Merise / 2 extensions. and compare some MERISE models to some UML diagrams.

In the part about the SQL language is presented gradually and is illustrated by many examples. In this part you will learn to manipulate, filter, sort, group data; create, modify, delete tables and assign or remove rights to certain users.

The authors have deliberately kept only the concrete side of the MERISE method and the SQL language, to allow the reader immediate immersion. They also offer many exercises including a detailed and guided case study to facilitate this assimilation [19].

Christian Soutou explains in his work how to construct a conceptual model in the form of a class diagram, how to transform it into a model of relational or object-relational data, in order to finally generate the desired SQL2 or SQL3 code [20].

\section{ABOUT MERISE}

A method is the implementation of a number of steps (methodological), an approach, principles, tools (traces, Standardized papers, computer, vocabulary ...).

Is for that, MERISE being a method proposes steps for the implementation and conduct of IT projects. MERISE is an acronym signifying Method of Studies and Realizations for Computer Systems for Companies, is the commonly and widely used for the study and design of database in France.

This method aims to replace a manual system of an organization by an automated system of information processing. It aims, firstly to demonstrate the potential problems of the existing system and, secondly, to make improvements to the system. The factors considered in the study are the capture, collection, storage, processing and transmission of information.

So, MERISE helps to undertake a study of the existing and move on to the actual design, if that is the solution, i.e. it proceeds as follows:

1. Study of the existing: Here one describes the existing structure that wants to say the real situation of the organization and how it functions. situation.

2. Diagnosis and criticism of the existing: What the problem is and how to improve the

3. Design and setting up of the new system: to propose the models that lead to the database or even to propose some interfaces and programming codes for the realization while using certain programming languages and management system of databases. To create the models, MERISE proceeds by the system of 3 carvings on 4 Levels [4].

All these steps can be summary in figure1.

\section{Schema comments}

Note that the steps and sub-steps of the MERISE approach are in line with the direction of the different arrows whose steps and sub-steps are linked to the preceding ones by several well-defined principles of cohesion and validation of the models represented by circles numbered in figure1, this consolidates the data processing.

As shown in the under graphic, the MERISE has two major steps for designing a database: Study, diagnosis and criticism of the existing and Design and implementation of new system.

For our case we will focus to demonstrate by an example the capital importance of the first phase that is study, diagnosis and criticism of the existing. 


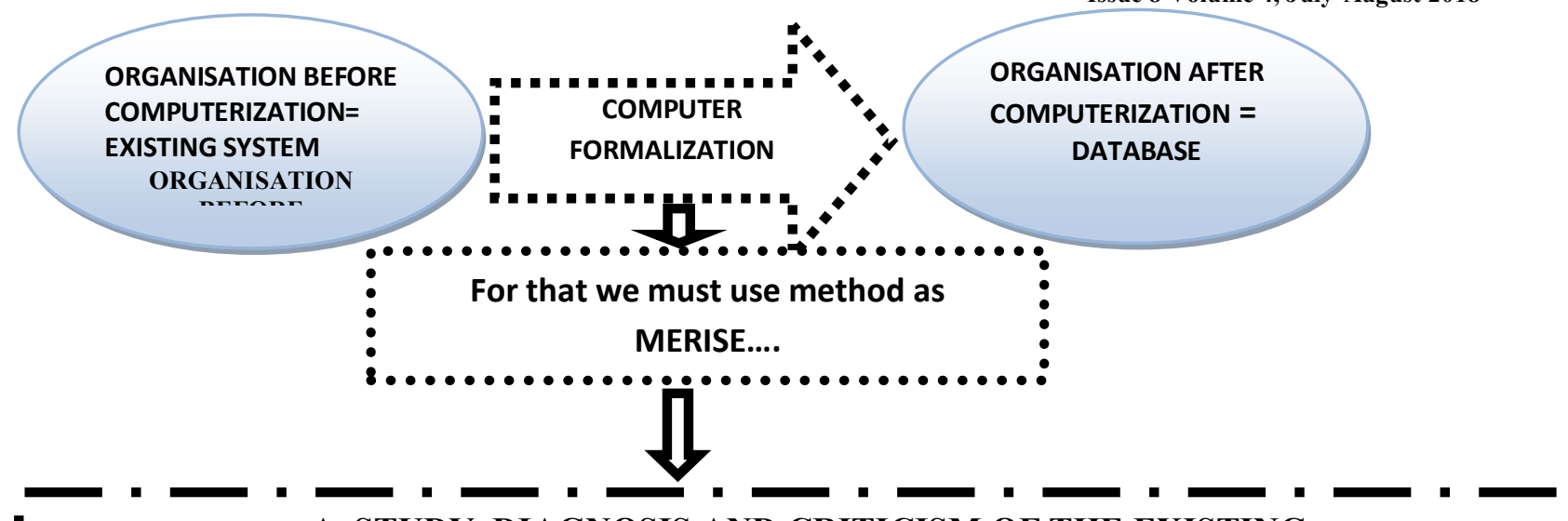

A. STUDY, DIAGNOSIS AND CRITICISM OF THE EXISTING

Sub Steps

1. THE LAUNCHING PHASE OF A PRE-STUDY

2. COLLECTION OF THE EXISTING

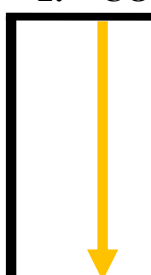

The information circuit

* Circulation and information processing scheme

* Workstation Description

* Operations Description

* Documents Description

* Data dictionary

3. DIAGNOSIS OF EXISTING

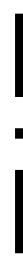

* Advantage of existing system

* Constraints

* Critics

* Proposal of the solution

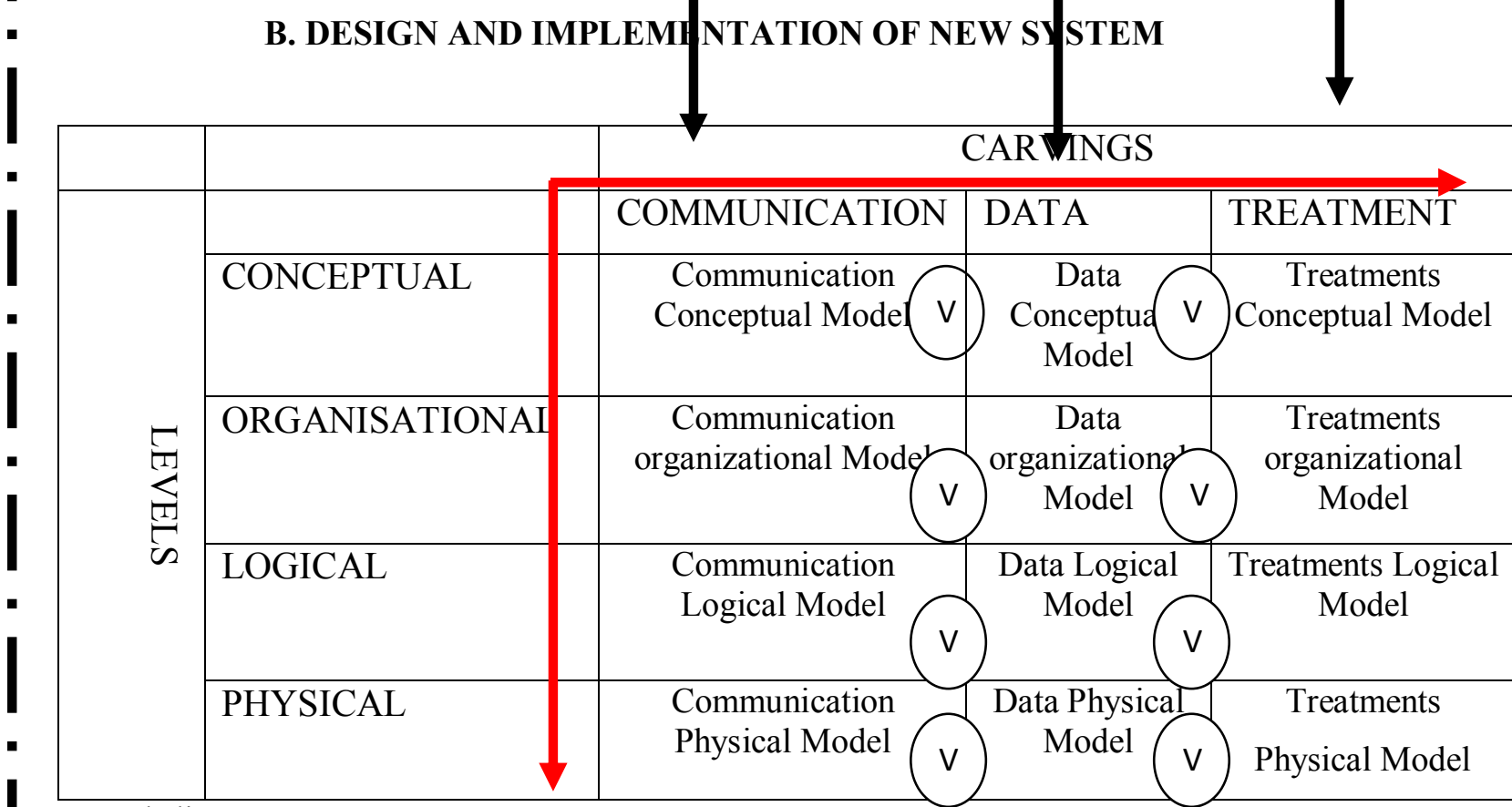

We symbolize the first Letter in all slots means the carving the following letter the level, and the last Means Model.

$\mathrm{CCM}=$ Communication Conceptual Model

- $\mathrm{DCM}=$ Data Conceptual Model

$\mathrm{TCM}=$ Treatments of Conceptual Model,...

The Letter V represents the model Validation

Figure 1 


\section{CASE STUDY: CONGOLESES (REPUBLIC DEMOCRATIQUE OF CONGO) COMPUTER CENTRE}

All documents, procedures those we will use in this work are taken from AGAPE/MAHGI one of Congolese's computer centre.

\section{THE LAUNCHING PHASE OF A PRE-STUDY}

Called preliminary analysis, this step aims to study the advisability of the project (is it useful compared to the real business goals?) And feasibility (Will the project is feasible from the constraints of realization as planning, finance ...?)

- On what, is based a study of computerization?

A preliminary study is available on the known elements from:

- A master plan that, provided by the company,

- On the expression of a need by a user.

In both cases, a prior interview is required, to properly know the real needs and strategic constraints.

\section{- What that the business manager expect this phase}

The preliminary study results in a draft after which the company's executives chose

1. Launch the realization,

2. Ask for further study, or

3. to abandon the project

\section{- Pre-study: Advisability and feasibility study}

Studying the opportunity of the project refers to examining its usefulness in relation to the real objectives of the company and the feasibility of a project refers to answering the question if the project is feasible in relation to the constraints of realization. Here we must be sure that opportunity and feasibility are confirmed then next step for collection of the existing can be done [18].

\section{COLLECTION OF THE EXISTING}

\subsection{Introduction}

This phase aims to identify and detail the actual needs for improvement to realize the project when it is timely and feasible.

And using certain tools includes:

- The circulation pattern: it is a tool that aims to give an accurate picture of circuits of information related to the case studied. It should be a graphical in interviews conducted workstations.

- The workstations and operation description: The workstations and operation description describe workstations and operation and give operational difficulties that require IT assistance.

- The document description: it aims to explain each rubric on the document management, written document, printed reports, manuscripts,...

This analytical tool is preparatory to the creation of the data dictionary that defines the all data of the studied area.

\subsection{Information Collection}

The collection used to define and describe the existing, and leads to an understanding of the current functioning of the information system concerned by the project.

\section{Principles}

This phase aims to improve knowledge of the observer about the field to analyze, on: internal and external actors, information systems (information circuit), documents, rules observed by the players in the management and technical vocabulary in the organization. 
It provides also to the next steps of MERISE method the "material", ie an inventory of documents and information. The result of this phase is evidenced by the use of 3 tools:

- The circulation pattern

- The workstations and operation description

- The document description

Before these sub stage actors must be defined:

- Internals Actors (only concern by computerization): Reception, Charged of office

- Externals Actors: Customer, Bookkeeper, material Provider, Executer Solicited Service, IT Chief Service

\subsubsection{The information circuit}

Here we see that the various documents bearing information exchanged between actors. This can be represented on a diagram called information circuit where the circles represent actors and arrows represent documents or actions numbered by their order of execution.

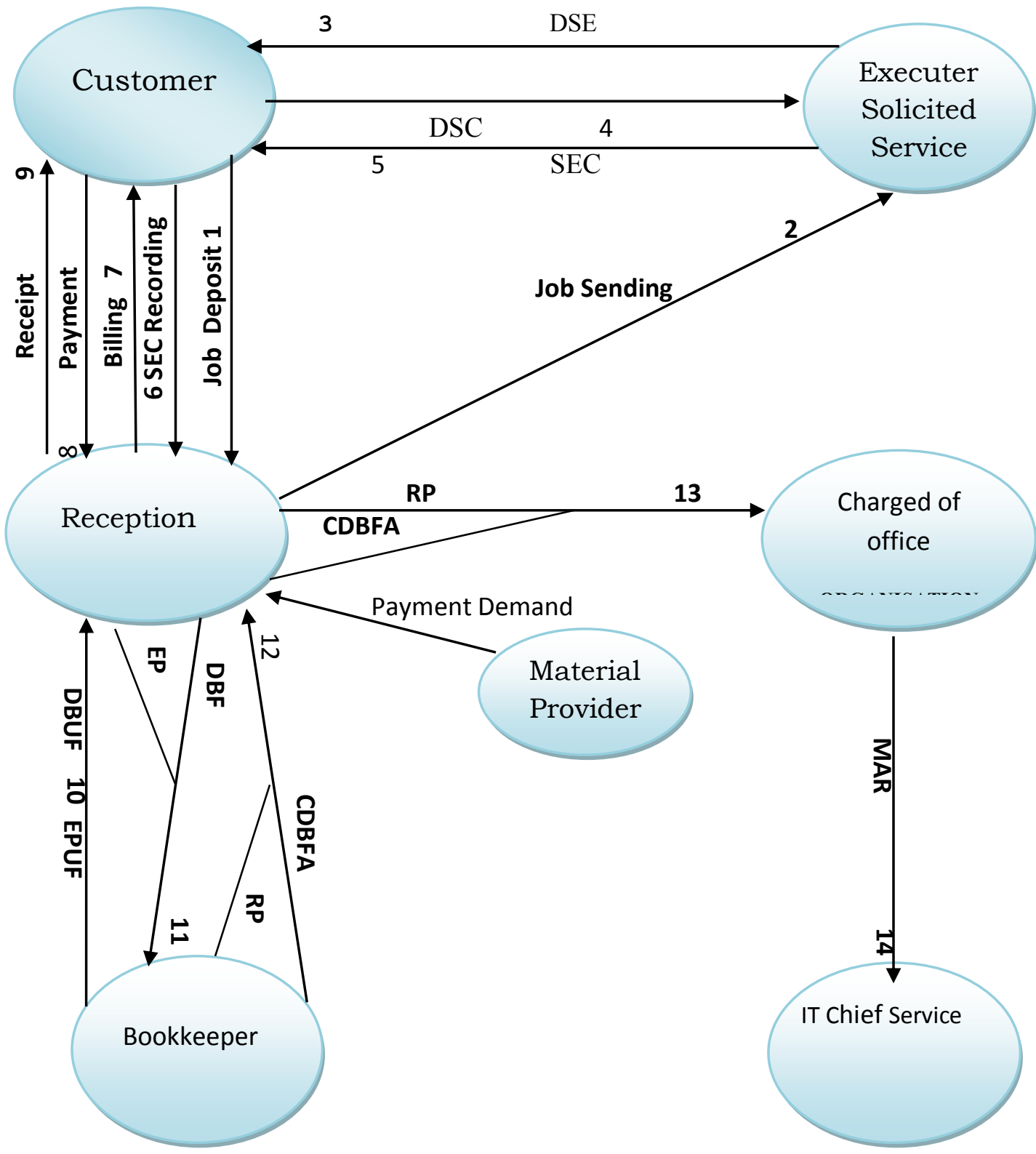

\section{LEGEND}

DSE : Draft Service Executed DSC : Draft Service Corrected. SEC : Service Executed Corrected DBUF: Daily Balance Unfilled BJR : Daily Balance Filled
RP : Receipt Paper

EP : Expense Paper

pı EPUF : Expense Paper Unfilled CDBFA: Copy of Daily Balance

MAR : Monthly Activities Report. 
DOI: https://dx.doi.org/10.26808/rs.ca.i8v4.05 International Journal of Computer Application (2250-1797) Issue 8 Volume 4, July-August 2018

This is the representation of the operations performed by the actors in the scheme of circulation and processing of information; it is in a table, the actors in the header, and carrying documents and Operations connected with arrows.

An operation is as follows:

\begin{tabular}{|c|}
\hline OPERATION NUMBER \\
\hline Operation Description \\
\hline
\end{tabular}

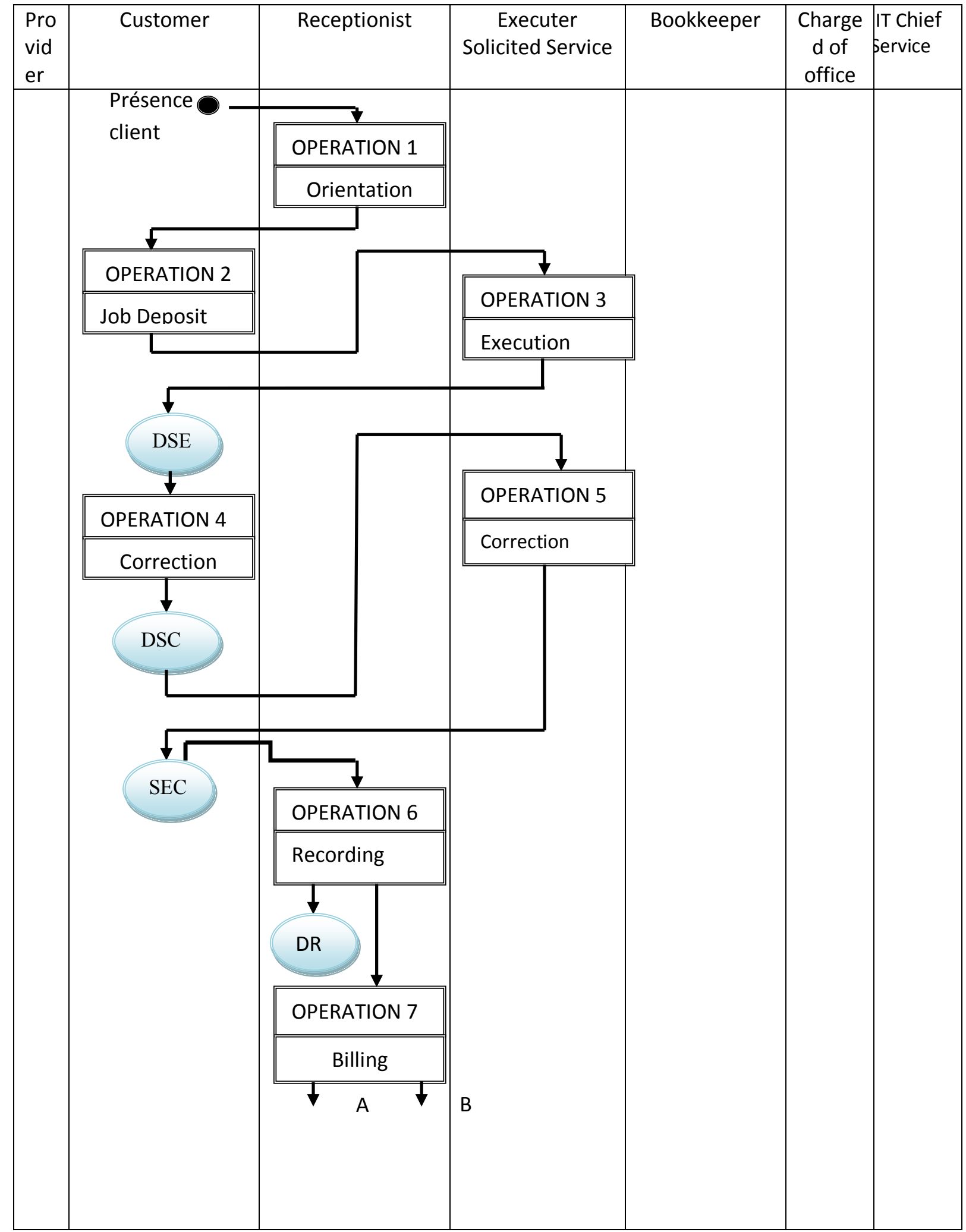


DOI: https://dx.doi.org/10.26808/rs.ca.i8v4.05 International Journal of Computer Application (2250-1797)

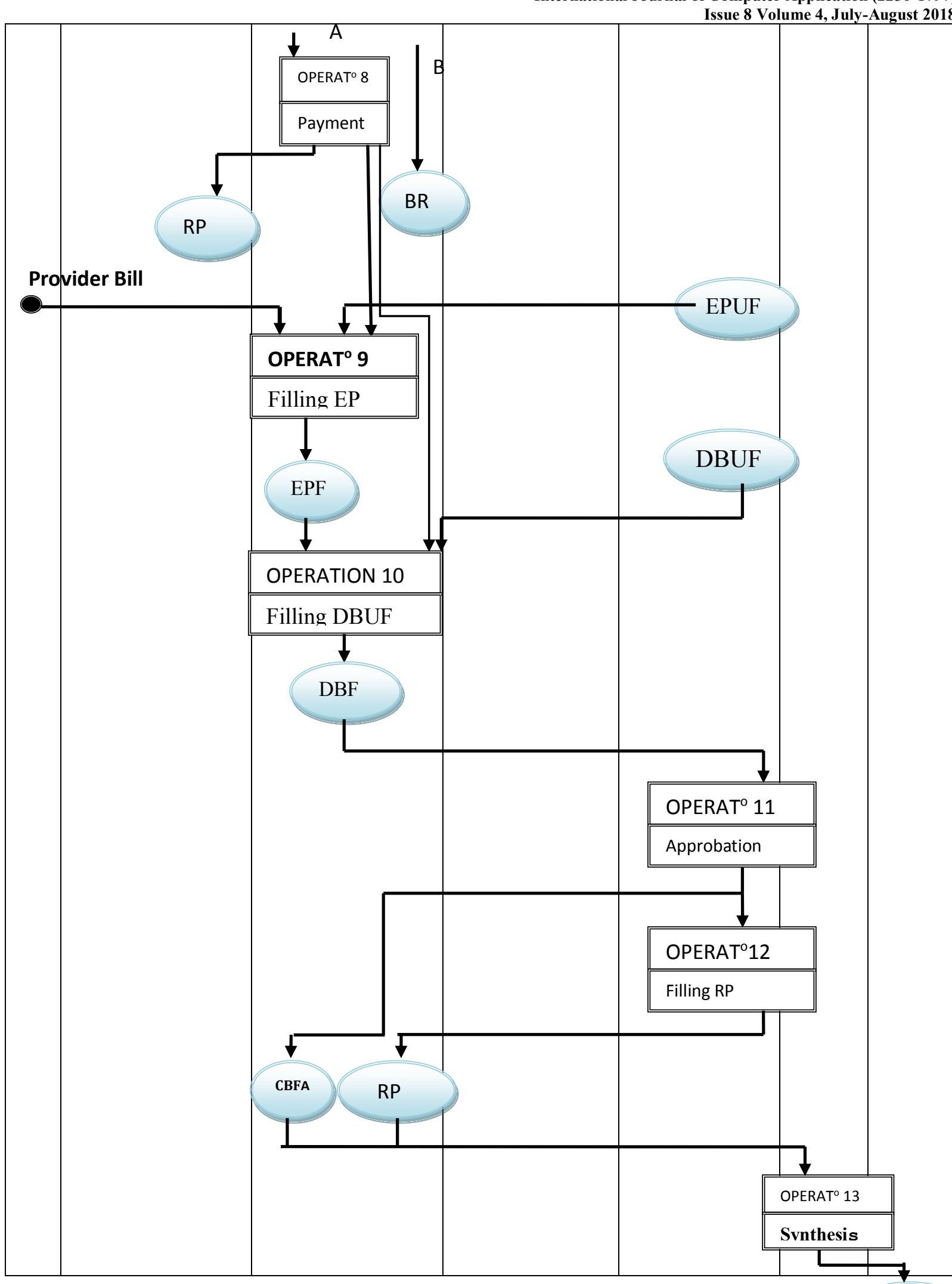

MAR 


\section{LEGEND}

DSE: Draft Service Executed

DSC: Draft Service Corrected.

SEC: Service Executed Corrected

DBUF: Daily Balance Unfilled

BJR: Daily Balance Filled

RP: Receipt Paper

EP: Expense Paper

EPUF: Expense Paper Unfilled

CDBFA: Copy of Daily Balance Filled Approved

MAR: Monthly Activities Report.

DR: Daily Register

BR: Bill Register

\subsubsection{Workstation Description}

A workstation can be defined by a structure composed of human, hardware and software resources to perform a specific job within an organization.

Thus, our internal actors with specific resources and jobs become work stations so each workstation is equal to the workstation.

NB. After this step we can already know which workstation to computerize.

\begin{tabular}{|c|c|c|c|c|c|}
\hline \multicolumn{6}{|c|}{ WORKSTATION DESCRIPTION } \\
\hline \multicolumn{6}{|c|}{ Name : Reception } \\
\hline \multicolumn{6}{|c|}{ Label : Reception } \\
\hline \multicolumn{6}{|c|}{ Place : IT Building } \\
\hline \multicolumn{6}{|c|}{ Timing : $9 \mathrm{~h}^{00} \mathrm{AM}$ to $3 \mathrm{~h}^{00} \mathrm{PM}$} \\
\hline \multicolumn{6}{|c|}{ OPERATIONS } \\
\hline $\bar{l}^{o}$ & Description & Type execution & Case/Day & Unity & Time/Day \\
\hline & & & & time/minute & \\
\hline 1 & Orientation & Oral & 20 & 3 & $60^{\prime}$ \\
\hline 2 & Customer recording & Manual & 20 & 5 & $100^{\prime}$ \\
\hline 3 & Billing & Manual & 20 & 5 & 100 \\
\hline 4 & Payment & Manual & 20 & 5 & 100 \\
\hline 5 & Filling Expense Paper & Manual & 5 & 5 , & 100 \\
\hline 6 & Filling Daily Balance & Manual & 1 & 30 ' & 30 ' \\
\hline \multicolumn{6}{|c|}{ RESSOURCES } \\
\hline \multicolumn{6}{|c|}{$\begin{array}{l}\text { Human : Bachelor } \\
\text { Hardware: Pen, Register, stump... } \\
\text { Software: non }\end{array}$} \\
\hline \multicolumn{6}{|c|}{$\begin{array}{l}\text { OBSERVATION } \\
\quad \text { If the recordling of receipts, expenses and Expense Paper, has been carried } \\
\text { out in a database, production of daily Balance would be automatic and time-saving } \\
\text { especially for receptionist who works more than } 8 \text { hours of Work at work without } \\
\text { break. }\end{array}$} \\
\hline
\end{tabular}




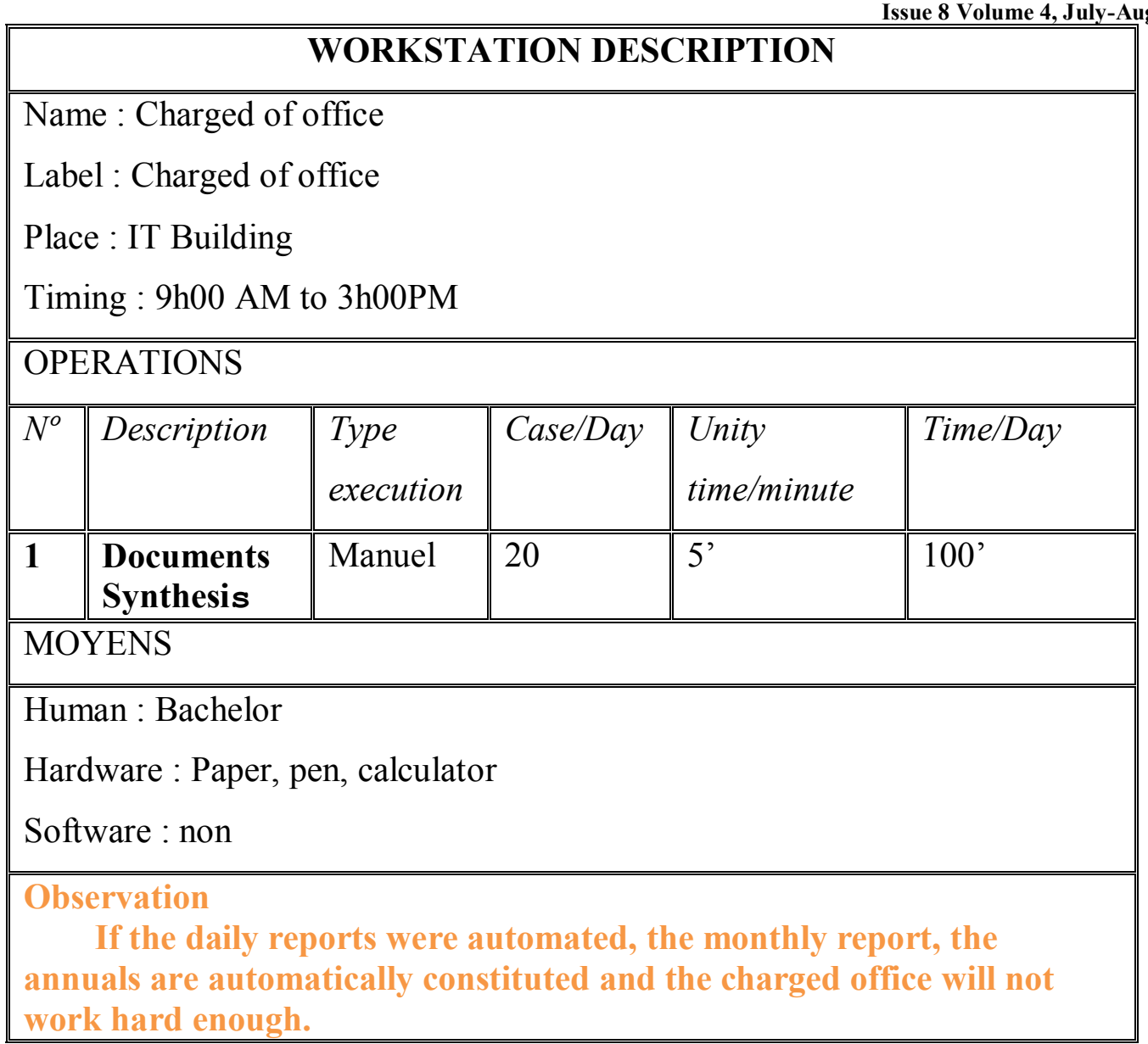

\subsubsection{Operations Descriptions}

Here we describe the internal actors operations of Internal WORKSTATIONS.

\begin{tabular}{|l||}
\hline \multicolumn{1}{|c|}{ OPERATION DESCRIPTION } \\
\hline Operation : $\mathrm{n}^{\mathrm{0}} 1$ \\
Label : orientation \\
Treatment Type: oral \\
Periodicity : $9 \mathrm{~h}^{00} \mathrm{AM}$ à $3 \mathrm{~h}^{00} \mathrm{PM}$ \\
\hline INPUT/OUTPUT \\
Input :Customer Arrival \\
Output :Get Service \\
\hline TRAITEMENT DESCRIPTION: The customer arrive, explain his \\
\hline demand and is oriented towards the service requested \\
\hline
\end{tabular}




\begin{tabular}{|l||}
\hline \multicolumn{1}{|c||}{ OPERATION DESCRIPTION } \\
\hline Operation $\mathrm{n}^{0} 6$ \\
Label : recording \\
Treatment Type: manual \\
Periodicity : $9 \mathrm{~h}^{00} \mathrm{AM}$ à $3 \mathrm{~h}^{00} \mathrm{PM}$ \\
\hline INPUT/OUTPUT \\
Input: Customer Arrival \\
Output : DR, Billing \\
\hline \hline TREATEMENT DESCRIPTION: Registration: customer number, \\
customer name, customer name, service requested, number of services \\
requested, unit price and total price.
\end{tabular}

\begin{tabular}{|l||}
\hline \multicolumn{1}{|c||}{ OPERATION DESCRIPTION } \\
\hline Operation $: \mathrm{n}^{0} 7$ \\
Label : Billing \\
Treatment Type: manual \\
Periodicity : $9 \mathrm{~h}^{00} \mathrm{AM}$ à $3 \mathrm{~h}^{00} \mathrm{PM}$ \\
\hline INPUT/OUTPUT \\
Input: number of services requested, Descriptions, unit price \\
Output: Total price of each service requested and total \\
\hline \hline TREATMENT DESCRIPTION calculate: \\
- The total price of each service requested $=$ number of service * Unit price \\
- General total (or payable) $=$ Total price1 + Total price $2+\ldots+$ Total price \\
\hline
\end{tabular}

\begin{tabular}{|l||}
\hline \multicolumn{1}{|c||}{ OPERATION DESCRIPTION } \\
\hline Operation $: \mathrm{n}^{\circ} 8$ \\
Label : Payment \\
Treatment Type: manual \\
Periodicity $: 9 \mathrm{~h}^{00} \mathrm{AM}$ à $3 \mathrm{~h}^{00} \mathrm{PM}$ \\
\hline INPUT/OUTPUT \\
Input : Recipe \\
Output : Receipt \\
\hline TREATMENT DESCRIPTION : \\
When the customer is billed, he pays (the service rendered billed) and is \\
given a receipt. \\
\hline
\end{tabular}




\begin{tabular}{|l||}
\hline \multicolumn{1}{|c||}{ OPERATION DESCRIPTION } \\
\hline \hline Operation : $\mathrm{n}^{\circ} 9$ \\
Label : Filling Expense Paper \\
Treatment Type: Manual \\
Periodicity : $9 \mathrm{~h}^{00} \mathrm{AM}$ à $3 \mathrm{~h}^{00} \mathrm{PM}$ \\
\hline INPUT/OUTPUT \\
INPUT : Amount, motive, title service, Description, Beneficiary \\
OUTPUT : EXPENSE PAPER \\
\hline $\begin{array}{l}\text { TREATMENT DESCRIPTION : } \\
\text { The name, post-name of the beneficiary, amount paid, reason, service } \\
\text { title and Description are filled in. }\end{array}$ \\
\hline
\end{tabular}

\begin{tabular}{|l||}
\hline \multicolumn{1}{|c||}{ OPERATION DESCRIPTION } \\
\hline \hline Operation : $\mathrm{n}^{\mathbf{0}} 10$ \\
Label : Filling of Daily Balance \\
Treatment Type: Manual \\
Periodicity: At the end of the day (A few minutes before 15h00) \\
\hline INPUT/OUTPUT \\
INPUT : Recipe and Expenses \\
OUTPUT : Remainder and Daily Balance Filled \\
\hline TREATMENT DESCRIPTION: \\
DB : Calculate the total Recipe, Expenses of each Description \\
- Remainder: Recipe - Expenses
\end{tabular}

\begin{tabular}{|c|}
\hline בPERATION DESCRIPTION \\
\hline Operation : $\mathrm{n}^{\circ} 13$ \\
\hline Label : Synthesis \\
\hline Treatment Type: Manual \\
\hline Periodicity : At the end of the month \\
\hline INPUT/OUTPUT \\
\hline INPUT : Activities of $1^{\mathrm{e}}$ Week, A $2^{\mathrm{e}} \mathrm{W}, \mathrm{A} 3^{\mathrm{e}} \mathrm{W}, \mathrm{A} 4^{\mathrm{e}} \mathrm{W}$ \\
\hline OUTPUT : Weekly Activities Report \\
\hline TREATMENT DESCRIPTION \\
\hline $\begin{array}{l}\text { Week Revenue=Sum (Sum Rev Day/Service) } \\
\text { Week Exnenses = Sum (Sum Exn Dav/serv) }\end{array}$ \\
\hline Remainder Week $=($ Week Rev - Week Expe $)$ \\
\hline
\end{tabular}

NB. This step prepares the material of the queries or views in DBMS.

A description is required for each operation, So many operations, so many descriptions. 


\subsubsection{Documents Description}

In this array we recover all rubrics those are on each document and specify their type (Date, picture...) Formulas is they are calculated, Obtaining Mode (Memorize taped on Keyboard, Calculated).

\begin{tabular}{|c|c|c|c|c|}
\hline \multicolumn{5}{|c|}{ "DOCUMENT DESCRIPTION } \\
\hline $\mathbf{N}^{\mathbf{0}}$ & Rubric & Type & $\begin{array}{l}\text { Formula or } \\
\text { constraint }\end{array}$ & $\begin{array}{c}\text { Obtaining } \\
\text { Mode }\end{array}$ \\
\hline$\overline{1}$ & Date Recipe or Expense Record & Date & - & $\bar{M}$ \\
\hline 2 & Customer Name & Text & & M \\
\hline 3 & Customer Post-Name & Text & - & M \\
\hline 4 & Service title & Text & - & M \\
\hline 5 & Service solicited number & Num. & - & M \\
\hline 6 & Bill Unit Price Service & $\mathrm{N}$ & - & M \\
\hline 7 & Bill Total Price service & $\mathrm{N}$ & - & Calcul \\
\hline 8 & Customer Id & $\mathrm{N}$ & SerSo numb* U.P & M \\
\hline 9 & Service Id & $\mathrm{N}$ & - & M \\
\hline
\end{tabular}

DOCUMENT DESCRIPTION

Document Name: BILL REGISTER

\begin{tabular}{|c|c|c|c|c|}
\hline$\overline{\mathbf{N}^{0}}$ & Rubric & Type & Formula or constraint & $\begin{array}{l}\text { Obtaining } \\
\text { Mode }\end{array}$ \\
\hline 1 & Bill Date & Date & - & Memorize \\
\hline 2 & Number Bill & $\mathrm{N}$ & - & M \\
\hline 3 & Customer Name & Text & - & $M$ \\
\hline 4 & Customer Post name & Text & - & $M$ \\
\hline 5 & Service solicited Number & $\mathrm{N}$ & - & M \\
\hline 6 & Service Title & Text & - & M \\
\hline 7 & Service Solicited U.P & $\mathrm{N}$ & - & M \\
\hline 8 & Bill Service T. P & $\mathrm{N}$ & BillServ Numb *U.P & Calcul \\
\hline 9 & Bill Observation Paym & Yes/No & - & M \\
\hline 10 & Customer Id & $\mathrm{N}$ & - & M \\
\hline 12 & Service Id & $\mathrm{N}$ & - & M \\
\hline
\end{tabular}


DOI: https://dx.doi.org/10.26808/rs.ca.i8v4.05 International Journal of Computer Application (2250-1797) DOCUMENT DESCRIPTION Issue 8 Volume 4, July-August 2018

Document Name: RECEIPT

\begin{tabular}{|c|c|c|c|c|}
\hline $\mathbf{N}^{\mathbf{0}}$ & Rubric & Type & Formula or constraint & Obtaining Mode \\
\hline 1 & ReceiptNumber & $\mathrm{N}$ & - & $\mathrm{M}$ \\
\hline 2 & ReceiptDate & Date & - & M \\
\hline 3 & Customer Name & Text & - & M \\
\hline 4 & Custom.PosaNam & Text & - & M \\
\hline 5 & ReceiptAmount & $\mathrm{N}$ & - & M \\
\hline 6 & ReceiptDescript. & Text & - & M \\
\hline 7 & Customer Id & $\mathrm{N}$ & - & M \\
\hline
\end{tabular}

DOCUMENT DESCRIPTION

Document Name: Expense Paper

\begin{tabular}{|c|c|c|c|c|}
\hline $\mathbf{N}^{\mathbf{0}}$ & Rubric & Type & Formula or constraint & Obtaining Mode \\
\hline$\overline{11}$ & Customer Id & Text & 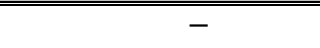 & $\overline{\mathrm{M}}$ \\
\hline 2 & Expense Desc & Text & -- & M \\
\hline 3 & ExpenseAmou & $\mathrm{N}$ & -- & M \\
\hline 4 & Expense Id & $\mathrm{N}$ & -- & M \\
\hline
\end{tabular}

\section{DOCUMENT DESCRIPTION}

Document Name: DAILY BALANCE

\begin{tabular}{|c|c|c|c|c|}
\hline$\overline{N^{0}}$ & Rubric & Type & Formula or constraint & Obtaining Mode \\
\hline 1 & Service Title & Text & - & $\mathrm{M}$ \\
\hline 2 & Recipe & $\mathrm{N}$ & Sum (ReceiptAmount) & Calcul \\
\hline 3 & Expense & $\mathrm{N}$ & Sum (ExpenseAmount) & Calcul \\
\hline 4 & Remainder & $\mathrm{N}$ & Recipe-Expense & Calcul \\
\hline 5 & Service Id & $\mathrm{N}$ & - & M \\
\hline 6 & Day operation & Date & -- & M \\
\hline
\end{tabular}

\section{DOCUMENT DESCRIPTION}

Document Name: MOTHLY ACTIVITIES REPPORT

\begin{tabular}{|c|c|c|c|c|}
\hline 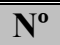 & Rubric & Type & Formula or constraint & Mode d'obten \\
\hline 1 & "Service Title & $\overline{\mathbf{A N}}$ & 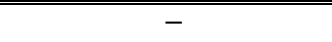 & $\overline{\mathbf{M}}$ \\
\hline 2 & Week & Date & - & Deducted \\
\hline 3 & SumRemainder & $\mathbf{N}$ & $\begin{array}{l}\text { Sum(Remain) per week } \\
\text { per service }\end{array}$ & $\begin{array}{l}\text { Calcul } \\
\text { Calcul }\end{array}$ \\
\hline 5 & LineTot & $\mathbf{N}$ & $\begin{array}{l}\text { Sum (Remainder)per } \\
\text { Service }\end{array}$ & $\begin{array}{l}\text { Calcul } \\
\text { Calcul }\end{array}$ \\
\hline 6 & ColumTot & $\mathbf{N}$ & Sum (Expense)per week & Calcul \\
\hline 7 & CodeService & $\mathbf{N}$ & - & $\mathbf{M}$ \\
\hline
\end{tabular}




\subsubsection{Data Dictionary}

On the basis of the various descriptions of the documents, a table is constituted from the rubrics on these documents and is called the Data Dictionary, note this Data Dictionary constitute the foundation of entity-Association Model.

This table contains the following columns: the number, mnemonic code, description, type of item and even the origin document.

The mnemonic code is the coding of each item on the various documents; it must be significant, short, without space and without special characters $\left(! @ \# \$ \%^{\wedge} \&^{*}() ?><\right.$ ?).

The detail of mnemonic code is made in Description columns.

We have some restrictions that the data dictionary should not have non calculated rubrics, non-redundancy, respect for semantic unity (one mnemonic $=$ one rubric), non-synonymous (customer name and client name), non- polysemy (CustNamePostName $=$ CustName and custPostName).

\begin{tabular}{|c|c|c|c|c|c|}
\hline $\mathrm{N}^{\mathrm{o}}$ & Mnemonic Code & Description & $\begin{array}{l}\text { Type } \\
\text { Rub }\end{array}$ & $\begin{array}{l}\text { Obtain. } \\
\text { M }\end{array}$ & $\begin{array}{l}\text { Origin. } \\
\text { Document }\end{array}$ \\
\hline & CustName & Customer Name & AN & $\mathrm{M}$ & $\overline{\mathrm{D} R+\mathrm{RP}+\mathrm{BR}}$ \\
\hline 2 & CustPostName & Customer Post name & AN & M & $\mathrm{DR}+\mathrm{RP}+\mathrm{BR}$ \\
\hline 3 & ServDescrip & Service Description & AN & M & DR \\
\hline & & & & & $\begin{array}{l}+\mathrm{BR}+\mathrm{DB}+\mathrm{MA} \\
\mathrm{R}\end{array}$ \\
\hline 4 & NumbServBill & Number service Billed & $\mathrm{N}$ & M & $\mathrm{DR}+\mathrm{BR}$ \\
\hline 5 & UnPriServBill & $\begin{array}{l}\text { Unitaire Prix Service } \\
\text { Billed }\end{array}$ & $\mathrm{N}$ & M & $\mathrm{DR}+\mathrm{BR}$ \\
\hline 6 & TotPriServBill & $\begin{array}{l}\text { Total Price service } \\
\text { Billed }\end{array}$ & $\mathrm{N}$ & Calc & $\mathrm{DR}+\mathrm{BR}$ \\
\hline 7 & BillObsPaym & $\begin{array}{l}\text { Bill Observation } \\
\text { payment }\end{array}$ & $\mathrm{O} / \mathrm{N}$ & M & $\mathrm{BR}$ \\
\hline 8 & BillDate & Bill Date & Date & M & $\mathrm{BR}$ \\
\hline 9 & BillNum & Bill Number & $\mathrm{N}$ & M & $\mathrm{BR}$ \\
\hline 10 & ReceiptNum & Receipt Number & $\mathrm{N}$ & M & $\mathrm{RP}$ \\
\hline 11 & RecDate & Receipt Date & Date & M & $\mathrm{RP}$ \\
\hline 12 & ReceitAmount & Receipt Amount & $\mathrm{N}$ & M & $\mathrm{RP}$ \\
\hline 13 & ReceiptDescript & Receipt Description & AN & M & $\mathrm{RP}$ \\
\hline 14 & Recipe & Recipe & $\mathrm{N}$ & Calc & DB \\
\hline 15 & Expense & Expense & $\mathrm{N}$ & Calc & DB \\
\hline 16 & Remainder & Remainder & $\mathrm{N}$ & Calc & DB \\
\hline 17 & ExpenPapNum & Expense paper & $\mathrm{N}$ & $\mathrm{M}$ & EP \\
\hline
\end{tabular}




\begin{tabular}{|c|c|c|c|c|c|}
\hline & & Number & & & \\
\hline 18 & ExpenPapNamBenef & $\begin{array}{l}\text { Expense Paper } \\
\text { Beneficiary Name }\end{array}$ & $\mathrm{AN}$ & M & EP \\
\hline 19 & $\begin{array}{l}\text { ExpenPapPostNamB } \\
\text { en. }\end{array}$ & $\begin{array}{l}\text { Expense Paper } \\
\text { Beneficiary Post } \\
\text { Name }\end{array}$ & $\mathrm{AN}$ & M & EP \\
\hline 20 & ExpenPapAmount & $\begin{array}{l}\text { Expense Paper } \\
\text { Amount }\end{array}$ & $\mathrm{N}$ & $\mathrm{M}$ & EP \\
\hline 21 & ExpenPapDesc & Expense Paper & $\mathrm{AN}$ & M & EP \\
\hline 22 & RecorExpenDate & $\begin{array}{l}\text { Recording Expense } \\
\text { Date }\end{array}$ & Date & M & EP \\
\hline 23 & Week & Week & Date & Induit & MAR \\
\hline 24 & SumRec & Sum Recipe & $\mathrm{N}$ & Calcu & MAR \\
\hline 25 & LinTot & line Total & $\mathrm{N}$ & Calcu & MAR \\
\hline 26 & ColTot & column Total & $\mathrm{N}$ & Calcu & MAR \\
\hline 27 & CustomCode & Customer Code & $\mathrm{N}$ & M & $\mathrm{DR}+\mathrm{RP}+\mathrm{BR}$ \\
\hline 28 & ServCode & service Code & $\mathrm{N}$ & $\mathrm{M}$ & $\begin{array}{l}\mathrm{DR} \\
+\mathrm{BR}+\mathrm{DB}+\mathrm{MA} \\
\mathrm{R}\end{array}$ \\
\hline
\end{tabular}

\section{LEGEND}

DR. $=$ DAILY REGISTER

$\mathrm{BR}=\mathrm{BILL}$ REGISTER

$\mathrm{RP}=\mathrm{RECEIPT}$

$\mathrm{EP}=$ Expense Paper

$\mathrm{DB}=\mathrm{DAILY}$ BALANCE

MAR=MOTHLY ACTIVITIES REPPORT

\section{DIAGNOSIS OF EXISTING}

We found in the main workstation (Reception) that the worker spends every 8 hours at work without rest, whereas if the recording of receipts and expenses would be done in a database, the production of the Daily Reports would be automatic and would save more time and especially that the continuation of work (the various reports) would be automatic and thus the head of the said service would be cleared then.

Similarly, the institution has several human and material assets to materialize the design and implementation of this database project.

This is that now we can think about something like a database design and realization, after the studies of existing. 


\section{CONCLUSION}

We have just proposed in this paper a study for a database design by its objective to study upstream the feasibility, the opportunity, the delimitation of the need expressed by an organization, see even the true's causes of the needs as expressed by the above diagnosis of study and analysis step of an existing in our case study.

Many have created databases that do not solve various business problems, such as heavy work, because usually due to bad administration, can never be solved by a database; because they didn't take into account the basic and specific factors in the design of the database is an important factor that can influence its exactitude and uselessness; this into account is done by the study and analysis step of an existing system to design a database. So any database design method cannot skip this mandatory step after this one, now the design and implementation of database can be done.

\section{REFERENCES}

1. Michel Diviné, Parlez-vous MERISE?, ed. Eyolles, 1994.

2. Muller, Pierre-Alain and Nathalie Gaertner. Modélisation objet avec UML. Scond Printing, Paris: Editions Eyrolles, 2000.

3. Rumbaugh, James at al. Object-Oriented Modeling and Design. , New York: General Electric Research and Development Center Schenectady, 2007

4. Michel Diviné, MERISE : 60 affaires classées, ed. Eyrolles, 1998, [Online], avalaible on $\mathrm{ftp} / / \mathrm{ftp}$-developpez.com/michel-divine/Merise60affairesclassees.pdf

5. Michelle CLOUSE, Algèbre relationnelle - Guide pratique de conception d une base de données relationnelle normalisée, Ellipses Marketing, 2008.

6. Gérard Bueno, Conception méthodique des bases de données- Un guide de bonne pratique, Ellipses Marketing, 2008.

7. Coulouris, George at al., Distributed Systems: Concepts and Design, Gordon Blair: Lancaster University, 5th Edition, 2012.

8. Gilles Roy, Conception de bases de données avec UML, Presses de l'Université du Québec, 2007.

9. Dessai, Bipin C. An Introduction to Database Systems. Galgotia Publication, 2006.

10. Jean-Patrick Mateheron, Comprendre MERISE outils conceptuels et organisationnels, ed. Eyrolles, Pairs, 1994.

11. Georges Gardarin, Bases de données Broché, Eyrolles, 5e Édition, 2003.

12. Elmasri Ramez et Shamkant Navathe, Conception et architecture des bases de données Pearson Education; 4e Édition, 2004.

13. Soutou, Christian, UML2 pour les bases de données, 2002.

14. Said Benaïchou, bases de données et systèmes d'information - modèle relationnel, sql, techniques avancées, modélisation, ellipses marketing, 2017.

15. Arnold Rochfeld et José Moréjon, La Méthode Merise, tome 3 : Gamme opératoire, Editions d'Organisation, 1989.

16. Imad Saleh, Les bases de données relationnelles : Conception et réalisation ,Hermes Science Publications, 1994.

17. Dominique Dionisi, L'essentiel sur Merise, Eyrolles; 2e Édition, 1998

18. Hubert Tardieu et al., La méthode MERISE principes et outils, ed. d'organisation, Paris, 2000.

19. Baptiste, Jean-Luc, Merise Guide pratique - Modélisation des données et des traitements manipulations avec le langage SQL, Eni Ressources informatiques, 2012.

20. Christian Soutou, De UML à SQL : Conception de bases de données, Eyrolles; Édition ,2002. 